\title{
Femtomolar Detection of Silver Nanoparticles by Flow-Enhanced Direct-Impact Voltammetry at a Microelectrode Array
}

\author{
Stanislav V. Sokolov, ${ }^{\dagger, \S}$ Thomas R. Bartlett, ${ }^{\dagger, \S}$ Peter Fair, ${ }^{\dagger}$ Stephen Fletcher, ${ }^{\dagger}$ and Richard G. Compton ${ }^{*}{ }^{\dagger}$ \\ ${ }^{\dagger}$ Department of Chemistry, Physical and Theoretical Chemistry Laboratory, Oxford University, South Parks Road Oxford, OX1 3QZ, \\ United Kingdom

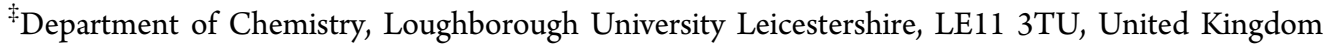

Supporting Information

ABSTRACT: We report the femtomolar detection of silver $(\mathrm{Ag})$ nanoparticles by direct-impact voltammetry. This is achieved through the use of a random array of microelectrodes (RAM) integrated into a purpose-built flow cell, allowing combined diffusion and convection to the electrode surface. A coupled RAM-flow cell system is implemented and is shown to give reproducible wall-jet type flow characteristics, using potassium ferrocyanide as a molecular redox species. The calibrated flow system is then used to detect and quantitatively size $\mathrm{Ag}$ nanoparticles at femtomolar concentrations. Under flow conditions, it is found the nanoparticle impact frequency increases linearly with the volumetric flow rate. The resulting limit of detection is more than 2 orders of magnitude smaller than the

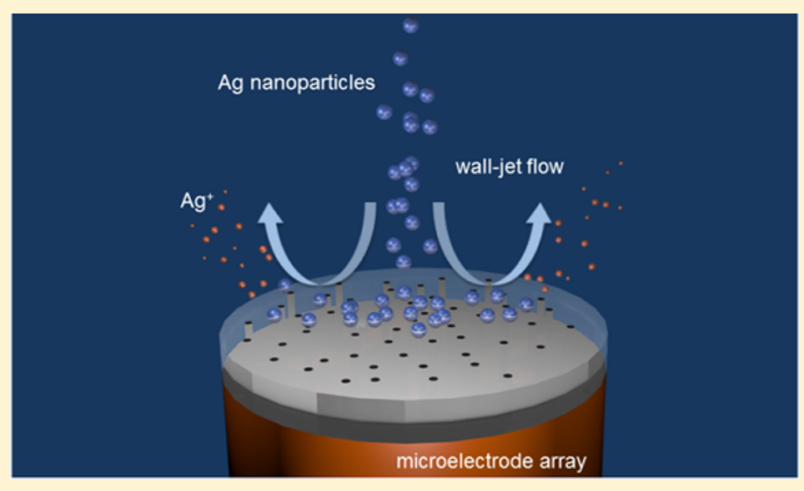
previous detection limit for direct-impact voltammetry (900 fM) [J. Ellison et al. Sens. Actuators, B 2014, 200, 47], and is more than 30 times smaller than the previous detection limit for mediated-impact voltammetry (83 fM) [T. M. Alligrant et al. Langmuir 2014, 30, 13462].

$\mathrm{T}$ here is considerable interest in nanoparticles (NPs) from both fundamental and application perspectives. ${ }^{1}$ Current methods for the detection and characterization of NPs are varied but primarily consist of optical techniques such as ultraviolet-visible light (UV-vis) spectroscopy, dynamic light scattering (DLS), or NP tracking analysis (NTA). UV-vis spectroscopy allows for the detection of monodisperse NP samples; yet, it is limited by inaccuracies in measuring polydisperse systems. ${ }^{2}$ This is a characteristic shared by DLS, which is significantly influenced by the scattering of larger particles and has been reported to have inaccuracies in population distributions of up to several orders in magnitude when dealing with polydisperse systems. ${ }^{2}$ NTA is less affected by polydispersity and can operate with samples consisting of $10^{7}-10^{9}$ particles per $\mathrm{mL}$, which is equivalent to a lower limit of detection of $16.6 \mathrm{fM} .^{3}$ However, a common feature shared by all optical detection methods is their cost and inability to analyze samples of poor optical clarity. ${ }^{4}$ Electrochemical detection is a potentially inexpensive and simple method for the detection and characterization of electroactive NPs that is indifferent to optical clarity but has previously relied largely on bulk drop-cast studies. ${ }^{5}$ Unfortunately, such methods cannot provide key information on the size distribution of the particles and have been shown to suffer from incomplete stripping, because of surface agglomeration/aggregation. ${ }^{6-8}$ This is a significant drawback and indicates the need for the continued development of new detection methods for NPs that provide both low detection limits and reliable particle size distributions.

Recent advancements in electrochemical NP sensing has seen the detection of single NPs via the "nanoimpacts" technique. Nanoimpacts can be classified in two broad categories: direct and mediated. Direct impacts involve Faradaic charge transfer between the particle and the electrode and subsequent reaction of the particle ${ }^{9}$ (e.g., dissolution), while mediated impacts involves charge transfer to solution species mediated via the colliding particle (e.g., hydrazine on the surface of platinum $(\mathrm{Pt}) \mathrm{NPs}) .{ }^{10}$ An example of the former case is the electro-oxidation of an impacting silver ( $\mathrm{Ag}) \mathrm{NP}$ :

$$
x \mathrm{Ag}(\text { nanoparticle }) \rightarrow x \mathrm{Ag}^{+}+x \mathrm{e}^{-}
$$

The arrival of a particle is indicated by a spike in current during the current-time transient. Each spike corresponds to an individual impact event and can be integrated to determine the charge, $Q:^{11}$

$$
Q=\int I \mathrm{~d} t=\frac{4 F \pi \rho r_{\mathrm{NP}}^{3}}{3 A_{\mathrm{r}}}
$$

Received: July 13, 2016

Accepted: August 5, 2016

Published: August 5, 2016 
where $I$ is the current, $F$ the Faraday constant, $\rho$ the density of the material, $r_{\mathrm{NP}}$ the radius of the $\mathrm{NP}$, and $A_{\mathrm{r}}$ is the relative atomic mass of the material. The spike charge provides quantitative information about the number of atoms in the NP and this charge transfer is known to be quantitative, even for particles are large as $100 \mathrm{~nm} .{ }^{12}$ If the latter is assumed to be spherical, then sizing information is obtainable using the equation $^{13}$

$$
D_{\mathrm{NP}}=2 \times \sqrt[3]{\frac{3 A_{\mathrm{r}} Q}{4 n F \pi \rho}}
$$

where $D_{\mathrm{NP}}$ is the spherical diameter of the particle $\left(D_{\mathrm{NP}}=2 \times\right.$ $\left.r_{\mathrm{NP}}\right)$ and $n$ is the number of electrons transferred per Ag atom. The direct-impact method allows both the concurrent measurement of concentration ${ }^{14}$ and the sizing of NPs, providing a significant benefit over other techniques. This method has been applied successfully to the detection of Ag NPs in both opaque solutions ${ }^{4}$ and seawater ${ }^{15}$ at a microdisk electrode. Ag NPs are an excellent model system for direct impacts and have been utilized for proof of concept works including shape determination, hindered diffusion effects, and agglomeration/ aggregation processes. ${ }^{16-18}$

The direct-impact technique has hitherto been conducted in stationary systems, relying on diffusional mass transport of particles to the microdisk electrode surface. Under these conditions, the use of microwire electrodes is thought to be optimal and has been shown to achieve a detection limit of 900 $\mathrm{fM}{ }^{19}$ Crooks and co-workers have developed an alternative mediated approach to detecting Ag NPs through functionalization of magnetic microbeads with multiple NPs and enhancing the collision rate of the functionalized beads with an ultramicroelectrode. The reported Ag detection limit was 61 $\mathrm{fM}^{20}$ For real-world applications sensors require low operating costs, simplicity of operation and fast response. Mediated and magnetically guided bead/particle impacts, ${ }^{20,21}$ while interesting from a research point of view, challenge these requirements and an alternative is warranted. In the present work, we focus on direct-impact electrochemistry.

Forced convection provides an additional and efficient way of increasing mass transport to an electrode surface by decreasing the diffusion layer thickness. ${ }^{22,23}$ Traditionally, rotating disk electrodes (RDEs) have been employed by electrochemists, because of the distinct advantages of laminar flow and wellestablished theory, which allows in-depth analysis of interfacial kinetics. ${ }^{24-26}$ However, flow cells have distinct advantages in that they are all-sealed units that are less prone to turbulence, and are readily adapted to colloidal systems. ${ }^{27}$ Flow cells have found applications in both research and industry, because of their online detection capabilities, with examples including heavy metal detection ${ }^{28}$ and biological redox processes. ${ }^{29}$ Recent work has also exploited enhanced mass transport by flow for the detection of NPs via the mediated-impact method and has achieved detection limits of $83 \mathrm{fM}^{30}$

As well as introducing convection, another clear avenue for enhancing detection limits for direct impacts is the use of larger electrode areas. To date, the majority of impact studies have used single microelectrodes, because of their enhanced radial diffusion, high signal-to-noise, and their lack of moving parts. However, the use of microelectrodes comes with limitations. They are known to have a high degree of fragility, making them unsuitable in some applications, ${ }^{31}$ and they often require extensive shielding to optimize the signal-to-noise $(\mathrm{S} / \mathrm{N})$ ratio. $^{32}$ Larger electrode areas have already shown to give enhanced detection limits by use of the microwire electrode ${ }^{19}$ but are not easily integrated into a flow regime. Therefore, an alternative is sought that provides an inherently high $\mathrm{S} / \mathrm{N}$ ratio while measuring the collision frequency under flow to allow low limits of detection. Arrays of gold (Au) microelectrodes with 25 $\mu \mathrm{m}$ for the smaller diameter and $30-180 \mu \mathrm{m}$ for the larger diameter have been adapted from conventional electronic integrated circuit chips. ${ }^{33,34}$ However, these are rather large, and smaller carbon electrodes are preferred for the present purposes. For this reason, we use the random array of microelectrodes (RAM) approach pioneered by Fletcher and Horne. $^{35}$ These RAMs consists of hundreds of carbon fibers connected in parallel to a current collector. This arrangement provides current amplification proportional to the number of active fibers, while maintaining radial diffusion. RAMs can also be repolished to provide a clean and reproducible surface, facilitating ease of use and maximizing applicability to real systems.

The ultimate limit of detection in impact electrochemistry is a single entity; however, the technique suffers because the time that is required for the entity to reach the probe by random walk alone can be on the order of tens of thousands of seconds for extremely dilute samples. ${ }^{18}$ Here, we describe a method to increase the rate with which entities collide with an electrode by invoking convective mass transfer using a flow cell, allowing for the analysis of femtomolar levels of Ag NPs. The flow response of the system is first characterized by the molecular redox species potassium ferrocyanide. This is then extended to the concurrent detection and sizing of citrate-capped Ag NPs at femtomolar concentrations with the effect of volumetric flow rate on the frequency of impacts reported.

\section{EXPERIMENTAL SECTION}

Chemical Reagents. Citrate-capped Ag NPs nominally 50 $\mathrm{nm}$ in diameter were purchased from nanoComposiX (San Diego, CA, USA) with a Ag content of $0.02 \mathrm{mg} \mathrm{mL}^{-1}$. These were independently characterized by DLS analysis (Malvern Zetasizer, Malvern, U.K.) and were found to be $58 \mathrm{~nm}$ in diameter. Therefore, the stock was calculated to have a Ag NP concentration of $31.0 \mathrm{pM}$. Potassium ferrocyanide $\left(\mathrm{K}_{4} \mathrm{Fe}-\right.$ $(\mathrm{CN})_{6}, 99.0 \%$ ) was supplied by $\mathrm{BDH}$ Chemicals (London, U.K.) and potassium chloride (KCl, $99.0 \%)$ by Sigma-Aldrich (Gillingham, U.K.). Water used for dilutions was distilled using a Millipore system to achieve a resistivity of $18.2 \mathrm{M} \Omega \mathrm{cm}$ at 298 K.

Electrochemical Instrumentation. A three-electrode system was used for all electrochemical measurements. The counter electrode was a graphite rod (Sigma-Aldrich) and the reference electrode was an in-house-fabricated $3 \mathrm{M} \mathrm{KCl}, \mathrm{Ag} /$ $\mathrm{AgCl}$ reference, with a potential of $-0.032 \mathrm{mV}$ vs SCE. Two $\mathrm{RAMs}^{35}$ were used as working electrodes for experiments, consisting of $\sim 7-\mu \mathrm{m}$-diameter carbon fibers insulated with cured epoxy resin and having an average electrode separation of $70 \mu \mathrm{m}$. While different RAMs were used in various experiments, the results have been normalized by the number of active fibers for each RAM to allow direct comparison. The number of active fibers varies between RAMs, because of the manufacturing process, and was calculated as follows. Cyclic voltammetry of the RAMs was conducted under stationary conditions in $1 \mathrm{mM} \mathrm{K}_{4} \mathrm{Fe}(\mathrm{CN})_{6}$ and $0.10 \mathrm{M} \mathrm{KCl}$ at $100 \mathrm{mV} \mathrm{s}^{-1}$ and is reported in Figure SI 1 in the Supporting Information. The limiting current obtained can be related to the number of 
active fibers $\left(N_{\text {fib }}\right)$, assuming a fiber diameter of $7 \mu \mathrm{m}$ and microdisk geometry:

$$
N_{\text {fib }}=\frac{I_{\text {lim }}}{4 r_{\text {disk }} n F D c *}
$$

where $I_{\text {lim }}$ is the limiting current, $r_{\text {disk }}$ the radius of the fiber, $D$ the diffusion coefficient, and $c^{*}$ the concentration of $\mathrm{K}_{4} \mathrm{Fe}$ $(\mathrm{CN})_{6}$. Using this equation, the RAMs were found to have 663 and 436 functional fibers, respectively. For initial flow cell characterization, an in-house-fabricated 4.15-mm-diameter glassy carbon (GC) electrode was used. Both an Autolab PGSTAT 302N (Metrohm-Autolab, Schiedam, The Netherlands) and an in-house-built low-noise potentiostat ${ }^{36}(250 \mathrm{~Hz}$ sampling rate, 4-pole Bessel filter) were used for all electrochemical experiments.

The chronoamperometry experiments performed for nanoimpact detection were conducted for $20 \mathrm{~s}$ with the vision of eventual practical applications, which require fast detection capabilities. The limit of detection can be further decreased by increasing the time scale of the experiment.

Flow Cell Instrumentation. The flow cell was designed and built in-house. It allows the interchange of working electrodes, with a washer allowing control over the inletworking electrode distance. A schematic design is shown in Figure 1, and full schematics are reported in the Supporting

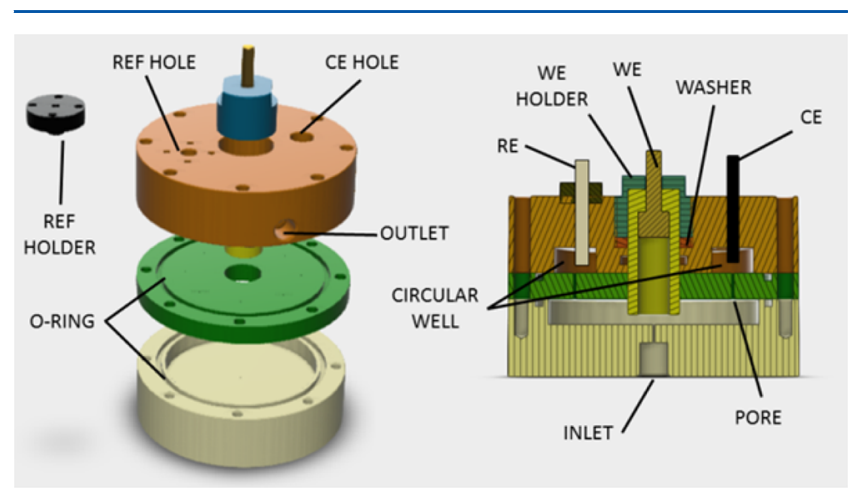

Figure 1. Expanded and cross-sectional views of the home-built flow cell. Full schematics are reported in the Supporting Information.

Information. Figure 1 shows the demountable flow cell system, which is built from three separate sections that are bolted together. The three main cell components were manufactured from polyether ether ketone (PEEK), with Delrin used for the reference and working electrode holder. During operation, solution is flowed through the cell, using a computer-controlled Fusion 100 Chemyx syringe pump (USA), and is injected onto the electrode surface through a $0.5-\mathrm{mm}$-diameter inlet hole. The inlet-electrode distance can be altered by using different washer thicknesses; however, the distance was maintained at 2 $\mathrm{mm}$ for all experiments conducted herein. The flow is then strained by the central component through 8 pores, each 0.5 $\mathrm{mm}$ in diameter, before passing into a pressure-equalizing well containing the counter and reference electrodes. The positioning of the electrodes in this cell ensures that the electroactive solution components cannot be affected by the counter electrode before reaching the working electrode.

Initial Flow Cell Characterization using a Glassy Carbon Macroelectrode. Initial characterization of the flow was carried out using a GC macroelectrode. Linear sweep voltammetry was conducted in $1 \mathrm{mM} \mathrm{K}_{4} \mathrm{Fe}(\mathrm{CN})_{6}$ and $0.10 \mathrm{M}$
$\mathrm{KCl}$ from $-0.05 \mathrm{~V}$ to $+0.70 \mathrm{~V}$ vs $\mathrm{Ag} / \mathrm{AgCl}$ over a range of volumetric flow rates. The results are reported in Figure SI 2 in the Supporting Information. Steady-state limiting current values $\left(I_{\text {lim }}\right)$ were obtained and plotted as $\log _{10}\left(I_{\text {lim }}\right)$ vs $\log _{10}$ (flow rate), as shown in Figure SI 3 in the Supporting Information to obtain a slope of $0.74 \pm 0.08$. This is in excellent agreement with the Levich equation for a wall jet with $I_{\lim } \propto V_{\mathrm{f}}^{3 / 4}:{ }^{37}$

$$
I_{\lim }=1.35 n \mathrm{FD}^{2 / 3} v^{-5 / 12} a^{-1 / 2} r_{\text {disk }}{ }^{3 / 4} V_{\mathrm{f}}^{3 / 4} c^{*}
$$

where $v$ is the kinematic viscosity, $\alpha$ the diameter of the jet nozzle, and $V_{\mathrm{f}}$ the volumetric flow rate.

\section{RESULTS AND DISCUSSION}

Prior to nanoimpact detection, the effects of flow on the steadystate response for molecular species was first studied. This provided an estimate of the possible increase in detectivity achievable by this system. Linear sweep voltammetry was conducted in $1 \mathrm{mM} \mathrm{K}_{4} \mathrm{Fe}(\mathrm{CN})_{6}$ and $0.10 \mathrm{M} \mathrm{KCl}$ from $-0.05 \mathrm{~V}$ to $+0.70 \mathrm{~V}$ vs $\mathrm{Ag} / \mathrm{AgCl}$ at $100 \mathrm{mV} \mathrm{s}^{-1}$ with a RAM across a range of flow rates. Figure 2 shows example voltammograms

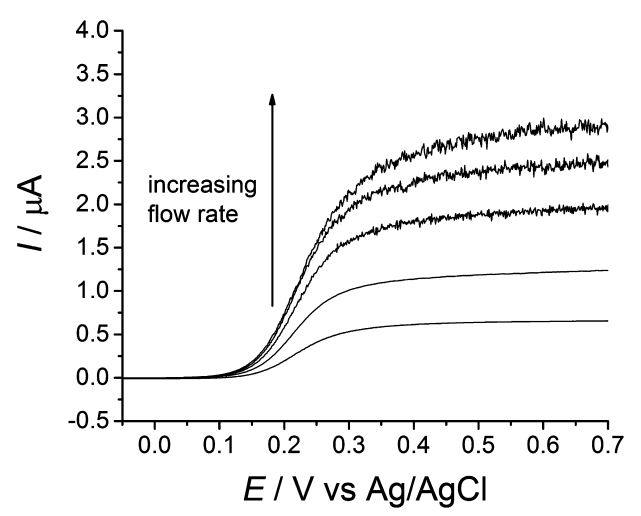

Figure 2. Flow dependence of RAM in $1 \mathrm{mM} \mathrm{K}_{4} \mathrm{Fe}(\mathrm{CN})_{6}+0.10 \mathrm{M}$

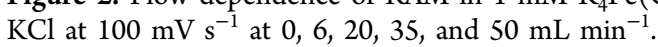

obtained at $0,6,20,35$, and $50 \mathrm{~mL} \mathrm{~min}^{-1}$. The RAM is found to give a steady-state response under stationary and flow conditions, confirming the diffusional independence of the individual microfibers in the RAM. As the volumetric flow increases, the steady-state response is maintained, along with an increase of the $I_{\text {lim }}$. Figure 3 shows a plot of $\log _{10}\left(I_{\text {lim }}\right)$ vs $\log _{10}$ (flow rate) for a range of flows from 0 to $50 \mathrm{~mL} \mathrm{~min}^{-1}$. A

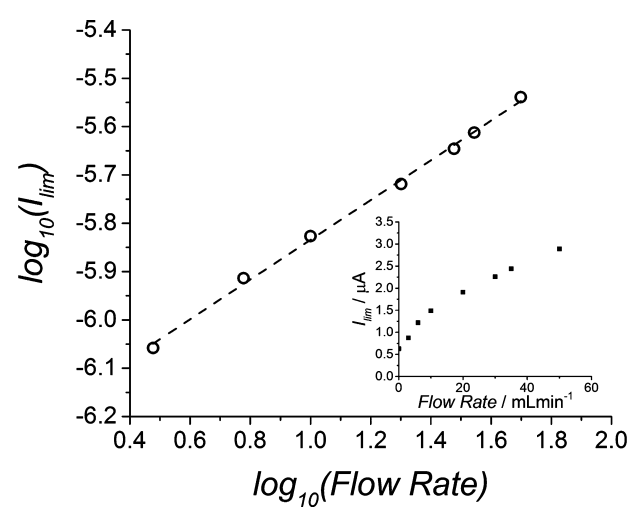

Figure 3. $\log / \log$ plot of $I_{\lim }$ vs volumetric flow rate for a RAM in 1 $\mathrm{mM} \mathrm{K}{ }_{4} \mathrm{Fe}(\mathrm{CN})_{6}+0.10 \mathrm{M} \mathrm{KCl}$ at $100 \mathrm{mV} \mathrm{s}^{-1}$ with a slope of $0.41 \pm$ 0.01 . Inset shows a plot of $I_{\text {lim }}$ versus the volumetric flow rate. 
clear trend is observed with a slope of $0.41 \pm 0.01$. The dependence of the transport limited current at the RAM with flow rate is less than that observed for the GC macroelectrode. This reflects the changed electrode geometry ${ }^{38}$ and indicates that the RAM is comprised of many microelectrodes, each of which has a lower sensitivity to flow, compared to a macroelectrode. The increase in $I_{\text {lim }}$ from a diffusional-only regime to the maximum volumetric flow rate used of $50 \mathrm{~mL}$ $\mathrm{min}^{-1}$ was found to be from $0.63 \mu \mathrm{A}$ to $2.90 \mu \mathrm{A}$, equivalent to an enhancement of signal of almost 5 times.

Next, the flow dependence of Ag NP impacts was conducted using the RAM-flow cell. Figure 4 shows current-time
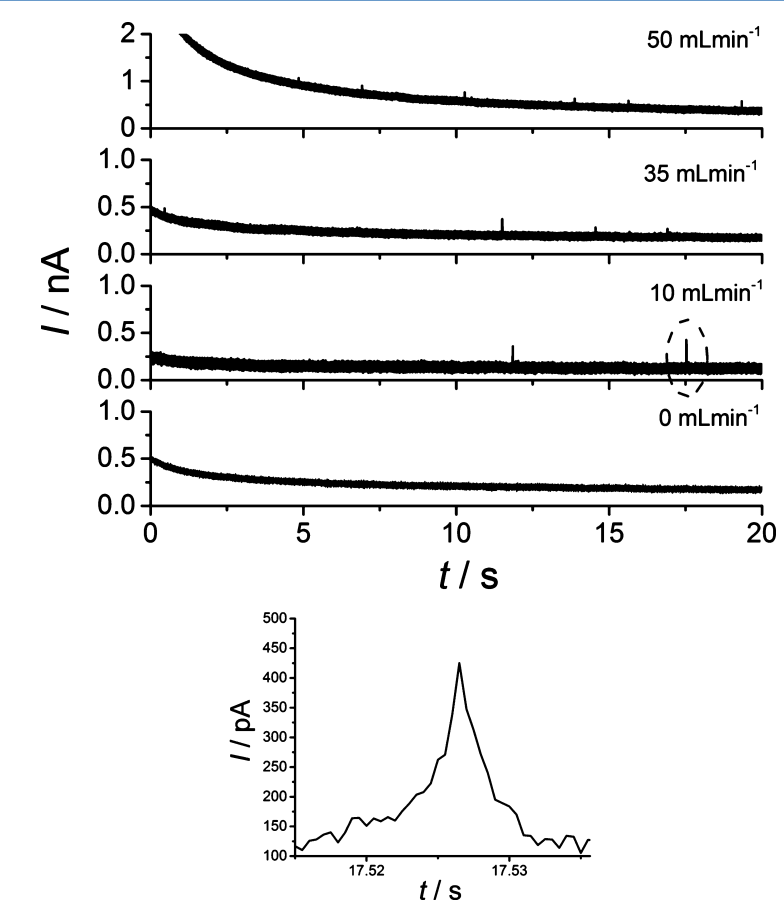

Figure 4. Example current-time transients recorded at varying flow rates showing nanoimpact spikes. Current-time transients were conducted at $+0.60 \mathrm{~V}$ vs $\mathrm{Ag} / \mathrm{AgCl}$ at a $\mathrm{Ag} \mathrm{NP}$ concentration of 6.2 $\mathrm{fM}$ in $40 \mathrm{mM} \mathrm{KCl}$. Inset shows an enlarged image of a current spike at $10 \mathrm{~mL} \min ^{-1}$ (circled region in top portion of the figure). The background consists mainly of capacitively coupled mains interference (50 $\mathrm{Hz}$ in the United Kingdom).

transients, $20 \mathrm{~s}$ in duration, at $+0.60 \mathrm{~V}$ vs $\mathrm{Ag} / \mathrm{AgCl}$ at a $\mathrm{NP}$ concentration of $6.2 \mathrm{fM}$ in $40 \mathrm{mM} \mathrm{KCl}$ across the experimental flow range of $0-50 \mathrm{~mL} \mathrm{~min}^{-1}$. This potential was chosen because it is suitable for the complete oxidation of Ag NPs up to $100 \mathrm{~nm}$ in diameter. ${ }^{12}$ No impacts were observed under stationary flow, because of the low concentration. When the NP suspension was flowed at $10 \mathrm{~mL} \mathrm{~min}{ }^{-1}$, current spikes were detected, indicative of $\mathrm{Ag} \mathrm{NP}$ oxidation. The frequency of spikes was observed to increase with increasing volumetric flow rate. The noise of the system was not significantly affected by flow rate and remained $<100 \mathrm{pA}$, even at the highest flow rate of $50 \mathrm{~mL} \mathrm{~min}{ }^{-1}$, allowing clear, unambiguous detection of the current spikes. The background current is likely due to surface oxidation of the RAM electrodes and/or residual citrate used for capping the particles. In order to validate that the current spikes observed were due to direct-impact voltammetry of the Ag NPs, these were analyzed using eq 3 to obtain the size distribution. This is shown in Figure SI 4 in the Supporting
Information, along with DLS characterization of the particles. The size of the particles determined by voltammetry and DLS was determined to be $57.0 \pm 1.5 \mathrm{~nm}$ and $58 \mathrm{~nm}$, respectively, confirming quantitative sizing of the particles alongside detection at a Ag NP concentration of $6.2 \mathrm{fM}$.

Finally, a lower concentration of $2.5 \mathrm{fM}$ NPs was studied under the same conditions. Figure 5 shows the change in

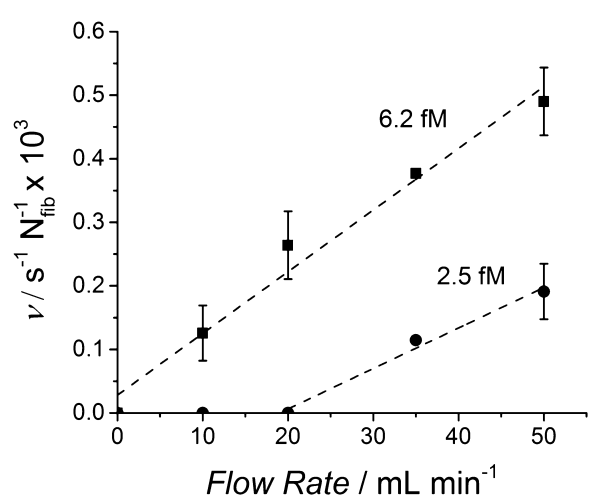

Figure 5. Nanoimpact frequency at RAMs at varying volumetric flow rates at a $\mathrm{Ag} \mathrm{NP}$ concentration of $6.2 \mathrm{fM}$ and $2.5 \mathrm{fM}$. Current-time transients were conducted at $+0.60 \mathrm{~V}$ vs $\mathrm{Ag} / \mathrm{AgCl}$ in $40 \mathrm{mM} \mathrm{KCl}$.

impact frequency with flow rate for this concentration and 6.2 $\mathrm{fM}$. No impacts were observed at a Ag NP concentration of 2.5 $\mathrm{fM}$ with volumetric flow rates up to $20 \mathrm{~mL} \mathrm{~min}^{-1}$. It can be seen that, for the lower concentration, high flow rates are required to detect particle impacts, and this stresses the benefits of flow over diffusion-only mass transport for NP impact voltammetry. At higher flows, however, NP impacts were detected. This is the lowest concentration of NPs ever used in a successful nanoimpact experiment, with an enhancement in experimental detectivity by 2 orders of magnitude over earlier attempts ${ }^{19}$ and by 1 order of magnitude for mediated impacts. ${ }^{30}$ Hitherto, the lowest reported experimentally detected concentration of NPs by direct impacts is $900 \mathrm{fM}$, using a carbon fiber microwire electrode. ${ }^{19}$ Nonspecific adsorption is inherent in NP chemistry and can have an effect on the concentration of NPs in suspension. As a result, a lower frequency of impacts may be observed, leading to errors in concentration estimates. In addition, care must be taken to minimize agglomeration/ aggregation during nanoimpact experiments. Readers interested in experimental aspects of the electrochemistry of particles are directed to the work of Tschulik et al. ${ }^{39}$

\section{CONCLUSIONS}

Femtomolar nanoparticle (NP) concentrations have been detected for the first time by direct-impact voltammetry, because of enhancement of mass transport by flow. The method detailed herein allows determination of the presence of NPs and their concurrent sizing. We have demonstrated that the frequency of impacts increases monotonically as the concentration increases. The actual frequency is likely to be affected by nonspecific adsorption and agglomeration, as discussed in previous works. ${ }^{21,30,40}$ This is an improvement of more than 2 orders of magnitude in the detection limit, relative to that previously reported. ${ }^{41}$ This extremely sensitive detection is a direct result of combining flow with a RAM electrode, increasing the signal-to-noise ratio. The presented method can be adjusted for sizing smaller NPs by choosing different array geometries in order to have suitable noise characteristics. This 
is of significant importance for the field of analytical NP detection and is a proof of principle for NP detection by directimpact voltammetry under flow conditions. Further applications of the developed methodology may include applications to biological systems with the objective of the development of point of care sensors for viruses and bacteria through simple yet highly efficient methods.

\section{ASSOCIATED CONTENT}

\section{S Supporting Information}

The Supporting Information is available free of charge on the ACS Publications website at DOI: 10.1021/acs.analchem.6b02670.

Flow cell characterization with GC electrode and NP size distributions from DLS and voltammetric studies (PDF) Flow cell schematics (PDF)

\section{AUTHOR INFORMATION}

\section{Corresponding Author}

*E-mail: richard.compton@chem.ox.ac.uk.

\section{Author Contributions}

${ }^{\S}$ These authors contributed equally to the work herein.

Notes

The authors declare no competing financial interest.

\section{ACKNOWLEDGMENTS}

The authors of this work acknowledge funding from the European Research Council (ERC) under the European Union's Seventh Framework Program (No. FP/2007-2013)/ ERC Grant Agreement No. [320403].

\section{REFERENCES}

(1) Murphy, M.; Ting, K.; Zhang, X.; Soo, C.; Zheng, Z. J. Nanomater. 2015, 2015, 1.

(2) Tomaszewska, E.; Soliwoda, K.; Kadziola, K.; Tkacz-Szczesna, B.; Celichowski, G.; Cichomski, M.; Szmaja, W.; Grobelny, J. J. Nanomater. 2013, 2013, 1.

(3) Filipe, V.; Hawe, A.; Jiskoot, W. Pharm. Res. 2010, 27, 796.

(4) Toh, H. S.; Compton, R. G. ChemistryOpen 2015, 4, 261.

(5) Ward Jones, S. E.; Campbell, F. W.; Baron, R.; Xiao, L.; Compton, R. G. J. Phys. Chem. C 2008, 112, 17820.

(6) Cloake, S. J.; Toh, H. S.; Lee, P. T.; Salter, C.; Johnston, C.; Compton, R. G. ChemistryOpen 2015, 4, 22.

(7) Toh, H. S.; Batchelor-McAuley, C.; Tschulik, K.; Uhlemann, M.; Crossley, A.; Compton, R. G. Nanoscale 2013, 5, 4884.

(8) Toh, H. S.; Jurkschat, K.; Compton, R. G. Chem.-Eur. J. 2015, 21, 2998.

(9) Cheng, W.; Compton, R. G. TrAC, Trends Anal. Chem. 2014, 58, 79.

(10) Xiao, X.; Bard, A. J. J. Am. Chem. Soc. 2007, 129, 9610.

(11) Zhou, Y. G.; Rees, N. V.; Compton, R. G. Angew. Chem., Int. Ed. 2011, 50, 4219 .

(12) Bartlett, T. R.; Sokolov, S. V.; Compton, R. G. ChemistryOpen 2015, 4, 600.

(13) Cheng, W.; Zhou, X. F.; Compton, R. G. Angew. Chem., Int. Ed. 2013, 52, 12980.

(14) Stuart, E. J. E.; Zhou, Y. G.; Rees, N. V.; Compton, R. G. RSC Adv. 2012, 2, 6879.

(15) Stuart, E. J. E.; Rees, N. V.; Cullen, J. T.; Compton, R. G. Nanoscale 2013, 5, 174.

(16) Sokolov, S. S.; Batchelor-McAuley, C.; Tschulik, K.; Fletcher, S.; Compton, R. G. Chem.-Eur. J. 2015, 21, 10741.

(17) Sokolov, S. V.; Tschulik, K.; Batchelor-McAuley, C.; Jurkschat, K.; Compton, R. G. Anal. Chem. 2015, 87, 10033.
(18) Kätelhön, E.; Compton, R. G. Chem. Sci. 2014, 5, 4592.

(19) Ellison, J.; Batchelor-Mcauley, C.; Tschulik, K.; Compton, R. G. Sens. Actuators, B 2014, 200, 47.

(20) Yoo, J. J.; Kim, J.; Crooks, R. M. Chem. Sci. 2015, 6, 6665.

(21) Robinson, D. A.; Yoo, J. J.; Castaneda, A. D.; Gu, B.; Dasari, R.; Crooks, R. M.; Stevenson, K. J. ACS Nano 2015, 9, 7583.

(22) Albery, J. Electrode Kinetics; Oxford University Press: Oxford, U.K., 1975.

(23) Bard, A. J.; Faulkner, L. R. Electrochemical Methods; Second Edition; John Wiley and Sons: New York, 2001.

(24) Sokolov, S. V.; Kätelhön, E.; Compton, R. G. J. Phys. Chem. C 2016, 120, 10629.

(25) Pleskov, Yu. V.; Filinovskii, V. Yu. The Rotating Disc Electrode (in Russ.); Consultants Bureau: New York, 1976 (ISBN 9780306109126).

(26) Koutecky, J.; Levich, B. G. Zh. Fiz. Khim. 1958, 32, 1565.

(27) Roberts, J. J.; Westgard, J. A.; Cooper, L. M.; Murray, R. W. J. Am. Chem. Soc. 2014, 136, 10783.

(28) Noyhouzer, T.; Mandler, D. Electroanalysis 2013, 25, 109.

(29) Deng, H.; Berkel, G. J. V. Electroanalysis 1999, 11, 857.

(30) Alligrant, T. M.; Anderson, M. J.; Dasari, R.; Stevenson, K. J.; Crooks, R. M. Langmuir 2014, 30, 13462.

(31) Compton, R. G.; Banks, C. E. Understanding Voltammetry; 2nd Edition; Imperial College Press: London, 2011.

(32) Weber, S. G. Anal. Chem. 1989, 61, 295.

(33) Matos, R. C.; Augelli, M. A.; Lago, C. L.; Angnes, L. Anal. Chim. Acta 2000, 404, 151.

(34) Rossier, J. S.; Girault, H. H. Lab Chip 2001, 1, 153.

(35) Fletcher, S.; Horne, M. D. Electrochem. Commun. 1999, 1, 502.

(36) Batchelor-McAuley, C.; Ellison, J.; Tschulik, K.; Hurst, P. L.; Boldt, R.; Compton, R. G. Analyst 2015, 140, 5048.

(37) Albery, W. J.; Brett, C. M. A. J. Electroanal. Chem. Interfacial Electrochem. 1983, 148, 201.

(38) Macpherson, J. V.; Unwin, P. R. Anal. Chem. 1998, 70, 2914.

(39) Tschulik, K.; Batchelor-McAuley, C.; Toh, H. S.; Stuart, E. J.; Compton, R. G. Phys. Chem. Chem. Phys. 2014, 16, 616.

(40) Jiang, J.; Huang, X.; Wang, L. J. Colloid Interface Sci. 2016, 467, 158.

(41) Lees, J. C.; Ellison, J.; Batchelor-McAuley, C.; Tschulik, K.; Damm, C.; Omanovic, D.; Compton, R. G. ChemPhysChem 2013, 14, 3895. 